\title{
A Pharmacognostic review of Liquorice: Pharmacological actions, Current uses and Future prospects
}

\author{
Available online at www.hjhs.co.in \\ REVIEW ARTICLE \\ Veer Jashvantbhai Patel *,a, Manish Mahebub Khetani ${ }^{\text {b }}$

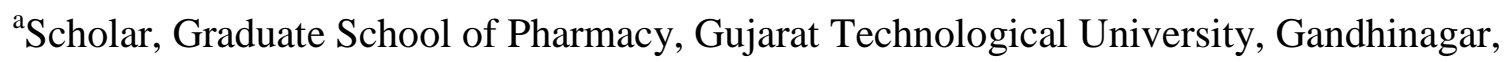 \\ Gujarat, India \\ ${ }^{\mathrm{b}}$ Student, Faculty of Pharmacy, Marwadi University, Rajkot, Gujarat, India \\ DOI 10.22270/hjhs.v6i2.99
}

\begin{abstract}
Herbs used as medicines are one of the widely adopted treatment alternatives which is in effect since ancient times. Herbal drugs are of great importance to the population because of its ease of availability and the relief of having no side effects. Majority of the herbal drugs are possessed to have more than one pharmacological effect. One such classic example of well-known herbal drug is Liquorice which is commonly known as Sweet Wood or Mulethi. Liquorice is available in dried root or rhizome form and it is widely used as natural sweetener, expectorant and as a hepato-protectant. The herb is widely grown in Baluchistan, Spain and in certain parts of Himalayan region of India. There are various active chemical compounds of Liquorice which include saponins and flavonoids. The pharmacological actions of this drug are attributed to its major active chemical compound named Glycyrrhizin. Liquorice is also found to have specific anti-viral activity against certain viral cells. The current article focusses on the pharmacognostic review of Liquorice and its uses. The multiple pharmacological effects of this drug and the future prospects of using Liquorice in developing formulations have been discussed in detail.
\end{abstract}

Keywords: Liquorice, Glycyrrhiza glabra, Glycyrrhizin, Herbal Drug, Anti-viral

\section{Introduction}

The current generation is rapidly shifting towards the use of herbal medicines as the primary choice for treatment of acute and chronic ailments and there has been a noticeable hike in the demand of various immunity boosting herbal drugs in the market. Due to the obvious idea of herbal drugs having less or almost null side effects, the population tends to choose herbal medicines over any other treatment options. (1) The use of herbal drugs for treatment is in effect since ancient times. The substantial evidence of herbal drugs used as remedy traces back to thousands of years ago in a cave at Iraq where the burial of a man was discovered. (2) Many developing countries rely upon herbal extracts and herbal drugs for treatment therapy as they are affordable and easily available. A majority of plant species are found to be having various phytochemicals, often referred to as primary and secondary metabolites which are useful for curing a number of ailments. These phytochemicals present in plant parts include bioactive components like alkaloids, glycosides, flavonoids, saponins, steroids and terpenes. Number of extracts from plant parts have been utilized for preparation of various herbal formulations. (1) One such classic example of herbal drug is Liquorice which belongs to Fabaceae family. Liquorice is well known since times for its ethnopharlacological properties. Liquorice, scientifically known as Glycyrrhiza glabra is one of the widely used herbal drugs since ancient times having a history of its use as a medicine as well as flavouring agent. Glycyrrhiza glabra, belonging to the Fabaceae (Leguminosae) Family is a perennial herb native to Mediterranean region, central and southwest Asia. Liquorice is also cultivated in China, France, Italy, Russia, USA and UK. (3) Pharmacognosy is the branch of pharmacy which deals with the 
study of cultivation, collection, standardization and authentication of crude drugs of natural origin obtained from plants and plant parts. (4) The current review focusses on giving a brief review on the pharmacognosy of Liquorice and highlights some significant uses and future scope of the same.

\section{Pharmacognostic Profile of} Glycyrrhiza glabra

Table 1. Vernacular names of Liquorice (Glycyrrhiza glabra) $(4,5)$

\begin{tabular}{|l|l|}
\hline \multicolumn{1}{|c|}{ Language } & \multicolumn{1}{|c}{ Synonyms/Vernacular Name of Liquorice } \\
\hline Sanskrit & Yastimadhu/Madhuk \\
\hline Hindi & Mulethi, Mulaithi, Mithilakadi, Kubassussa \\
\hline Gujarati & Jethi Madh \\
\hline Bengali & Yastomadhu, Jashtimadhu, Jaishbomodhu \\
\hline Tamil & Atimadhurama, Atimadhurappala \\
\hline Marathi & Jyeshtamadh \\
\hline Kannada & Samgara \\
\hline Karnataki & Valliyashtimadhu \\
\hline Punjabi & Mularthi \\
\hline Oriya & Jatimadhu \\
\hline Arab & Aslussiesa \\
\hline Perisa & Ausareha mahaka \\
\hline German & Sussholz \\
\hline
\end{tabular}

In some parts of the world, it is also known as Sweet wood, Glycyrrhiza and Glycyrrhizae radix. $(4,5)$

\section{Botanical Source}

The drug Liquorice is obtained from the dried roots, rhizome or stolon of Glycyrrhiza glabra Linne., also known as Spanish Liquorice in the commercial market or from the dried roots and rhizomes of Glycyrrhiza glabra Linne. var Glandulifera Waldstein et Kitaibel, also known as Russian Liquorice in the commercial market, both belonging to the Leguminosae (Fabaceae) family. (6)

\section{Geographical Source}

\section{Synonym and Vernacular Names}

Glycyrrhiza is derived from the combination of greek words, glykos meaning sweet and rhiza meaning root. Glycyrrhiza glabra is well known by different names in different geographical location acorss the world. It is commonly known was Liquorice or Licorice and Liquorice root. 


\section{Habitat}

Liquorice also known as Sweet Wood belongs to Leguminosae Family and it is grown in sub-tropical and warm temperate regions of the world. It requires a fertile sandy or clay soil near a river or a waterfilled region. It is native to Arabia, Afghanistan, Gulf and southwest Asia and the root is cultivated in Punjab, SubHimalayan region and Andaman Island. Liquorice herb is indigenous to several areas of Eurasia, North Africa and West Asia. (4)

\section{Scientific classification:}

Kingdom: Plantae

Division: Phanerogams

Subdivision: Angiospermae

Class: Dicots

Subclass: Polypetalae

Order: Calciflorae

Family: Leguminosae

Subfamily: Papilionaceae

Genus: Glycyrrhiza

Species: Glabra (4)

\section{General Description}

Color: Yellowish-brown to dark brown in external appearance and yellowish color in appearance, internally.

Odour: Characteristic

Taste: Sweet

Size: $20-50 \mathrm{~cm}$ in length and $2 \mathrm{~cm}$ in diameter

Shape: The unpeeled form is mostly straight to cylindrical in shape, while the peeled form is angular. (6)

\section{Harvesting}

The roots of Liquorice are generally harvested within 3 to 4 years after plantation. The rhizomes and roots are harvested in the month of October from those plants bearing no fruits, thus confirming maximum sweetness. The rootlets are removed manually and drug is washed with running water after which it is sun dried and then dried under shade until it loses $50 \%$ of its initial weight. (6)

\section{Morphology}

Herb: Glycyrrhiza glabra Linn is a hardy perennial shrub, attaining a height up to $2.5 \mathrm{~m}$. The leaves are compound, imparipinnate, alternate and 7 to $15 \mathrm{~cm}$ long, having 4-7 pairs of oblong, elliptical or lanceolate leaflets.

Flower: The flowers are narrow typically papilionaceous, borne in axillary spikes, pale whitish blue to purple or lavender in colour.

Calyx: The calyx is short, campanulate, with lanceolate tips and bearing glandular hairs.

Fruit: The fruit is a compressed legume or pod, up to $1.5 \mathrm{~cm}$ long, erect, glabrous usually containing 3-5 brown, reniform seeds.

Root: The taproot is stoloniferous and approximately $1.5 \mathrm{~cm}$ long and subdivides into 3-5 subsidiary roots, about $1.25 \mathrm{~cm}$ long, from which the stolons arise. These may reach $8 \mathrm{~m}$ and when dried and cut, together with the root, constitute commercial liquorice.It may be found peeled or unpeeled. The pieces of root break with a fibrous fracture, revealing the yellowish interior with a characteristic odour and sweet taste. $(1,7)$

\section{Chemical Constituents}

Saponins: The active chemical constituent I Glycyrrhiza glabra is Glycyrrhizin - a saponin derivative. It is a triterpenoid saponin and it is a mixture of potassium and calcicum salts of glycyrrhizic acid and it is 60 times sweeter than cane sugar.

Flavanoids: Flavonoid rich fractions include liquiritin, isoliquiritin liquiritigenin, neoliquiritin and rhamnoliquirilin. Liquiritin is a chalcone derivative which is responsible for the 
yellow color of the drug. The root contains glycyrrhiziniz acid, glycyrrhizin, saponins, sugar, aspargin, starch, resin, gum, mucilage, calcium and magnesium salts. The bark contains Tannins in small quantities.

Isofalvones: Isoflavonoid derivatives present in licorice include glabridin, galbrene, glabrone, shinpterocarpin, licoisoflavones A and B, formononetin, glyzarin and kumatakenin.
Other Constituents: In addition, four isoprenoid-substituted phenolic constituents (isoangustone A, semilicoisoflavone $\mathrm{B}$, licoriphenone, and 1-methoxyficifolinol), kanzonol $\mathrm{R}$ (prenylated isoflavan derivative) and several volatile components (pentanol, tetramethyl pyrazine, hexanol, terpinen-4ol, linalool oxide A and B, geraniol, and $\alpha$ terpineol) have also been reported. $(1,5,8)$

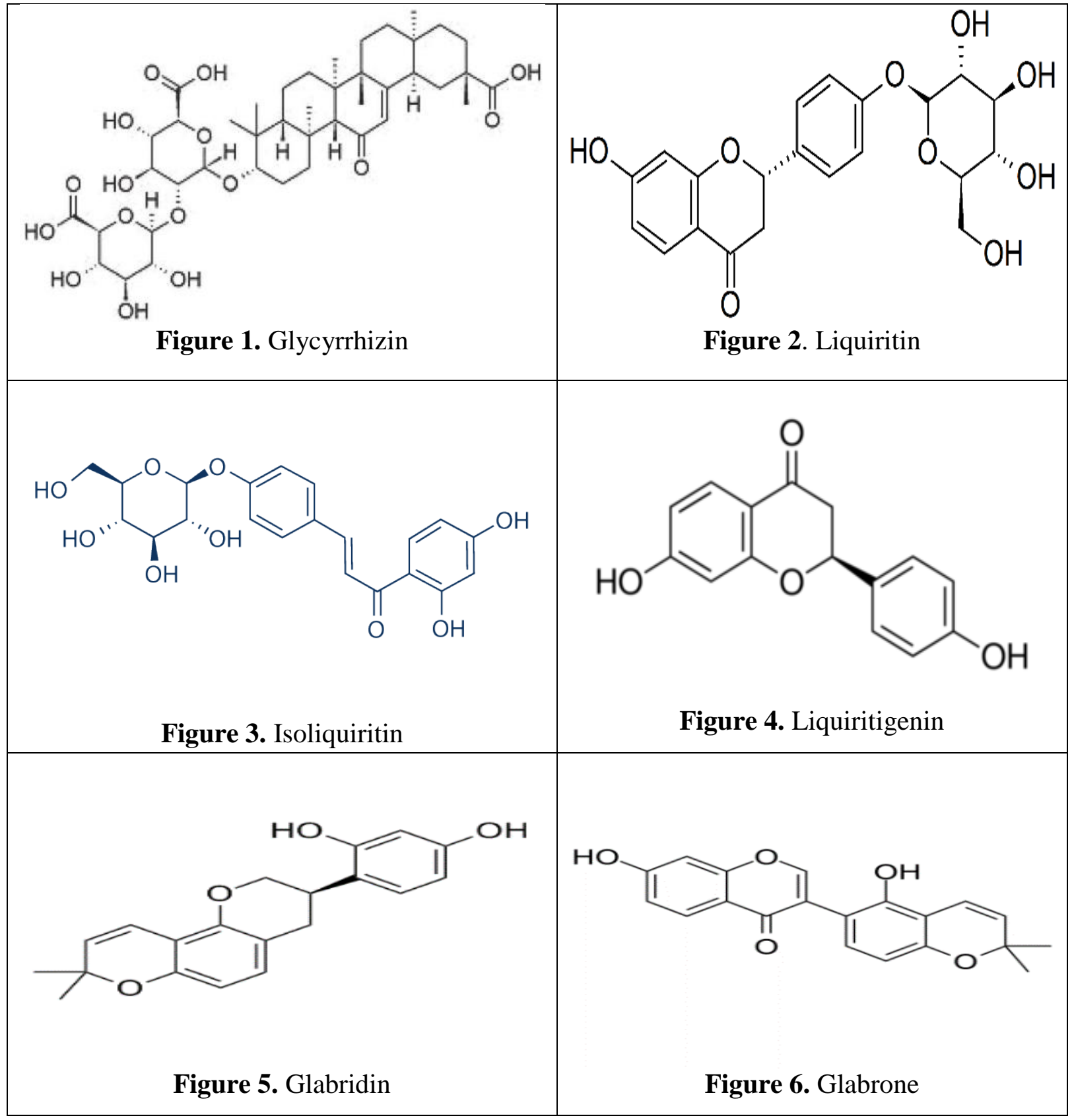




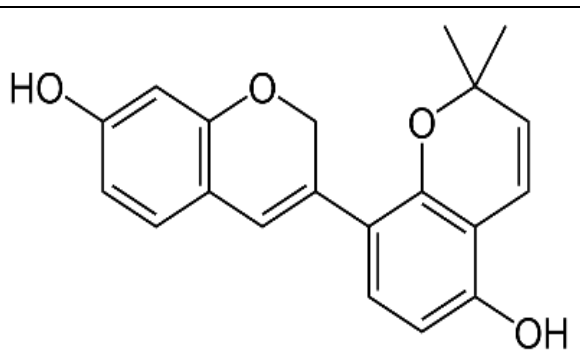

Figure 7. Glabrene

\section{Mechanism of Action of Liquorice and its active chemical constituents}

\section{Pharmacological Activity}

Glycyrrhizin and glycyrrhizic acid have shown to inhibit growth of viral genomes and cytopathology of certain RNA and DNA viruses. Some chemical constituents of Liquorice have anti-inflammatory activity similar to that of steroids like hydrocortisone. The isoflavones glabridin and hispaglabridins $\mathrm{A}$ and $\mathrm{B}$ have significant antioxidant activity and both glabridin and glabrene possess estrogenlike activity. (7)

\section{Anti-oxidant and Anti-bacterial Activity}

The root extracts of Liquorice have presence of active chemical constituents like saponins and flavonoids because of which it possesses anti-oxidant and antibacterial activity. It is widely known as scavenger as it actively fights against free radicals in certain diseased conditions like carcinogenicity and also builds immunity against bacterial infections. (8)

\section{Anti-viral Activity}

Liquorice is used in treatment of several viral infections, as it is found to possess anti-viral activity because it does not allow viral cell binding thereby inhibiting viral replication. (8)

\section{Anti-inflammatory Activity}

In several animal model studies, betaglycyrrhitinic acid has presented noticeable anti-inflammatory activity. The anti-inflammatory action is thought to be present because of the inhibitory action of , beta-glycyrrhitinic acid on glucocorticoid metabolism. It inhibits the action of 11 hydroxysteroid hydroxygenase and causes accumulation of glucocorticoids thereby exhibiting its anti-inflammatory action. (8)

\section{Anti-coagulant and Memory Enhancer}

Glycyrrhizin is found to be the first plant-based thrombin inhibitor. It causes prolongation in thrombin and fibrinogen clotting time and increases plasma recalcification duration. One laboratorybased research study showed the memory enhancing property of Glycyrrhiza glabra in animals. (5)

\section{Anti-ulcer Activity}

Liquorice has been in use for treatment of ulcers since 1970s because of its constituents - glycyrrhizin and deglycyrrhizinated licorice (DGL). Licorice roots contain Carbenoxolone which is having anti-ulcer effects and it prevents ulcers in the stomach by inhibiting the secretion of gastrin. (5)

\section{Anti-mutagenic Activity}

Hydromehanolic extract of Liquorice roots have shown to exhibit anti-mutagenic potential by supressing micro-nucleus formation in chromosomal activity in bone marrow cells of albino mice. (5)

\section{Anti-hyperglycaemic Activity}

Kalaiarasi P. et al. carried out the study about the anti-hyperglycaemic effect of $\beta$ glycyrrhetinic acid on streptozotocindiabetic rats. Diabetes was induced in adult male albino rats by administration of streptozotocin (40 mg/kg of body weight) intraperitoneally. Diabetic rats showed increase of plasma glucose and 
glycosylated haemoglobin (HbA1c) and a decrease of plasma insulin and haemoglobin. Activities of gluconeogenic enzymes such as glucose 6-phosphatase, fructose 1, 6-bisphosphatase increased and glucokinase, glucose 6- phosphate dehydrogenase decreased in the liver along with glycogen. Oral administration of $18 \beta$ glycyrrhetinic acid $(50,100$, or 200 $\mathrm{mg} / \mathrm{kg} /$ body weight) or glibenclamide (600 $\mu \mathrm{g} / \mathrm{kg} /$ body weight) in $5 \%$ dimethyl sulfoxide, for 45 days, prevented the above changes and improved towards normal blood glucose levels. (7)

\section{Hepatprotective Activity}

Glycyrrhizin has been in use for more than 60 years in Japan in treatment of chronic Hepatitis as it has shown decrease in serum aminotransferases level. A research conducted showed that hydromethanloicc extract of Glycyrrhiza glbara root exhibited significant protection

Table 2. Phytochemical tests for Liquorice (9)

\begin{tabular}{|c|l|}
\hline Sr. No. & Phyto-constituent \\
\hline $\mathbf{1}$ & Saponins \\
\hline $\mathbf{2}$ & Phenols \\
\hline $\mathbf{3}$ & Flavonoids \\
\hline $\mathbf{4}$ & Steroids \\
\hline $\mathbf{5}$ & Triterpenes \\
\hline $\mathbf{6}$ & Alkaloids \\
\hline $\mathbf{7}$ & Lignans \\
\hline
\end{tabular}

\section{Traditional Use}

Traditionally, Glycyrrhiza glabra has been in use as a sweetener and flavouring agent in several foods and medicines. The plant itself has been in use since ancient times as a prophylaxis for gastric and duodenal ulcers owing to its anti-ulcer activity. Licorice has been in use for treatment of cough because of its antitussive and expectorant properties. It is also used as a laxative, galactogogue, antiasthmatic, antacid and anti-viral agent. It is also used as one of the major ingredients in medicinal oils used for treatment of epilepsy, paralysis and rheumatism. Liquorice is an important ingredient in from hepatot-toxicity induced in mice by Carbon-tetrachloride $\left(\mathrm{CCl}_{4}\right)$. (5)

\section{Immunomodulator Activity}

Glycyrrhizic acid present in Liquorice plant acts as a potential source of immunemodulator as it prevents virus growth and aids in inactivation of viral particles. (5)

\section{Anti-demulcent Activity}

Hydrated extract of Liquorice is found to be useful in treatment of cough and sore throat as it loosens the tracheal mucous secretion thereby exhibiting its anti-tussive and expectorant action. The active constituent - glycyrrhizin is responsible for the anti-demulcent action. (8)

\section{Phyto-chemical Tests}

Various preliminary phytochemical tests for Liquorice include the following (9):

Tests for phytochemical detection
Foam Test
Phenol Test
Shinoda Test
Salkowski Test
Salkowski Test
Mayers Test
Labat Test

'Liquorice compound powder' wherein it accelerates the action of senna. Liquorice liquid extract is used in the treatment of peptic ulcer. $(6,8,9)$

\section{Scope of Glycyrrhiza glabra as a Medicine in the Future}

Glycyrrhiza glabra is tending to have more than one property thus exhibiting a number of medicinal properties that can be useful in treatment of various acute and chronic ailments. One of the interesting mechanisms of Glycyrrhizin is that it prevents the growth of viral cell by inhibition of viral cell replication and viral cell binding. 
Alzheimer's disease is a neurodegenerative disorder characterized by amnesia and episodes of depression, apathy and psychosis. Certain species of Glycyrrhiza were examined for treatment of Alzheimer's disease, in which a noteable amount of improvement was observed due to anti-oxidant effect. There was a noted neuro-prtoective activity. Thus, there is a scope for development of glycyrrhizin-based medications that would help in treatment management of clinical symptoms of Alzheimer patients. (1)

A study conducted on anti-viral activities of ribavirin, pyraziofurin, mycophenolic acid and glycyrrhizin against two clinical isolates of SARS (Severe Acute Respiratory Syndrome) virus, i.e. FEM-1 and FEM-2 revealed that out of all, glycyrrhizin was most effective in controlling viral replication and could be used as a prophylaxis. Thus, studies like this and few others indicating potential of Liquorice in causing anti-viral effect has opened the way for researching more on the specific effects for current virus like SARS-CoV-2 and many other future epidemics that may tend to cause because of virus transmission. Liquorice due to its anti-viral and anti-inflammatory activity has a broad scope for development of pharmaceuticals or drugs that can cure or prevent the ailments caused due to viruses in severe conditions. Liquorice, as a drug has had a wide importance since times immemorial and the rational and correct use of it for the betterment of the healthcare of the entire human civilization can prove as a milestone in the healthcare industry. (5)

\section{Conclusion}

The younger population has shown a drastic change in their interest towards herbal remedies as herbal medicines are obtained from natural sources and they possess less or no side effects I comparison to the commercial available medications. A number of herbal medicines have been used since thousands of years which have multiple pharmacological effects. One such drug is Liquorice, also known as Mulethi or Jethi Madh, is having a number of benefits because of its active chemical constituent - glycyrrhizin which is 60 times sweeter than cane sugar. Liquorice is used in treatment of certain ailments like hepatitis, stomach ulcer, sore throat, etc. since ancient times. Recently several studies have shown that many of its chemical constituents have shown anti-inflammatory as well as anti-viral effects because of which the drug is in high demand. Liquorice is having various pharmacological effects like anti-tussive, anti-diabetic, anti-inflammatory, antioxidant, anti-bacterial and anti-viral. There is a wide scope for development of potent medications using Liquorice for treatment of life-threatening viral diseases.

\section{Acknowledgements}

Authors are very thankful to Himalayan Journal of Health Sciences for publishing our article.

Financial Disclosure statement: The author received no specific funding for this work.

\section{Conflict of Interest}

The authors declare that there is no conflict of interest regarding the publication of this article.

\section{References}

1. El-Saber Batiha G, Magdy Beshbishy A, ElMleeh A, Abdel-Daim MM, Prasad Devkota H. Traditional Uses, Bioactive Chemical Constituents, and Pharmacological and Toxicological Activities of Glycyrrhiza glabra L. (Fabaceae). Biomolecules. 2020 Feb 25;10(3):1-19.

2. Kunle Oluyemisi Folashade, Egharevba Henry Omoregie1, Ahmadu Peter Ochogu. Standardization of Herbal Medicines - A Review. International Journal of Biodiversity and Conversation. 2012 Mar;4(3):101-112.

3. Pastorino G, Cornara L, Soares S, Rodrigues F, Oliveira MBPP. Liquorice (Glycyrrhiza glabra): A phytochemical and pharmacological review. Phytotherapy Research. 2018 Aug 17;32(12):2323-2339. 
4. Dr Kaveri V. Rasal et al. Pharmacognostic Study Of Glycyrrhiza glabra Linn- A Review. International Ayurvedic Medical Journal. 2016 Oct;4(10):3188-3193.

5. Sharma V, Katiyar A, Agrawal R.C. Glycyrrhiza glabra: Chemistry and Pharmacological Activity. Sweeteners Reference Series in Phytochemistry. 2018:87100.

6. ePharmacogonosy. Liquorice. 2012 Oct 04 [Internet]. Epharmacognosy; 2012[cited 2021 Mar 21] Available from:

http://www.epharmacognosy.com/2012/04/liqu orice-synonyms-glycyrrhiza.html

7. Jalal Bayati Zadeh, Zahra Moradi Kor, Masoud Karimi Goftar. Licorice (Glycyrrhiza glabra Linn) As a Valuable Medicinal Plant. International Journal of Advanced Biological and Biomedical Research. 2013;1(10):12811288.

8. Khalid Hussain et al. A Review: Medicinal Importance of Glycyrrhiza glabra L. (Fabaceae Family). Global Journal of Pharmacology. 2014;8(1):8-13.

9. Swati P, Jyothi G, Shreya J, Vijay Danapur. Preliminary Phytochemical and Pharmacognostic Studies on a Well-known Medicinal Plant Glycyrrhiza glabra. International Journal of Pharmacognosy and Chinese Medicine. 2019 Dec 24;3(4):01-05. 